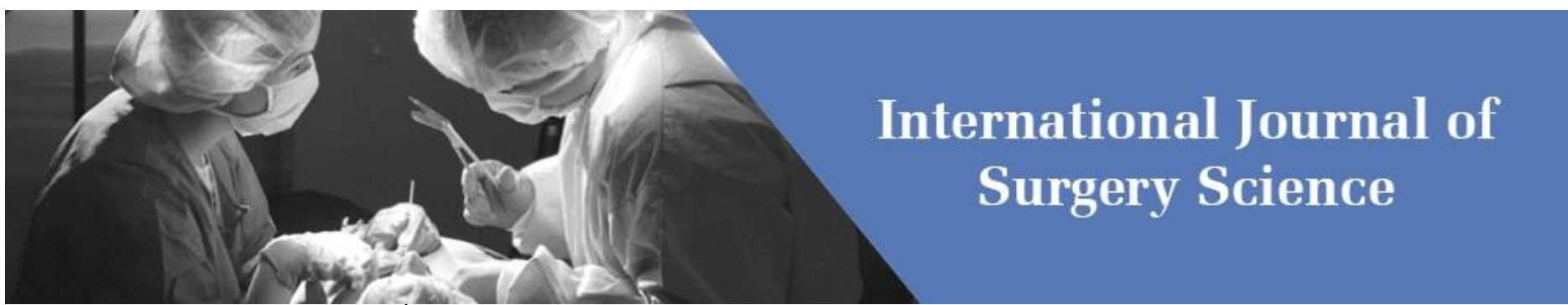

E-ISSN: 2616-3470

P-ISSN: 2616-3462

(C) Surgery Science

www.surgeryscience.com

$2019 ; 3(4): 220-222$

Received: 16-08-2019

Accepted: 18-09-2019

Ndong A

General Surgery Department, Aristide Le

Dantec Hospital, Dakar, Senegal

Diallo AC

General Surgery Department, Aristide Le Dantec Hospital, Dakar, Senegal

Faye M

General Surgery Department, Aristide Le Dantec Hospital, Dakar, Senegal

Ndiaye M

General Surgery Department, Aristide Le Dantec Hospital, Dakar, Senegal

Diouf A

General Surgery Department, Aristide Le Dantec Hospital, Dakar, Senegal

Faye PM

General Surgery Department, Aristide Le Dantec Hospital, Dakar, Senegal

Niasse A

General Surgery Department, Aristide Le Dantec Hospital, Dakar, Senegal

\section{Thiam JA}

Joliot-Curie Institute, Aristide Le Dantec Hospital, Dakar, Senegal

Sarr ISS

General Surgery Department, Aristide Le Dantec Hospital, Dakar, Senegal

Seye Y

General Surgery Department, Aristide Le Dantec Hospital, Dakar, Senegal

Gueye ML

General Surgery Department, Aristide Le Dantec Hospital, Dakar, Senegal

\section{Thiam 0}

General Surgery Department, Aristide Le Dantec Hospital, Dakar, Senegal

Seck M

General Surgery Department, Aristide Le Dantec Hospital, Dakar, Senegal

Touré AO

General Surgery Department, Aristide Le Dantec Hospital, Dakar, Senegal

Cissé M

General Surgery Department, Aristide Le Dantec Hospital, Dakar, Senegal

Ka 0

General Surgery Department, Aristide Le Dantec Hospital, Dakar, Senegal

Dieng $\mathbf{M}$

General Surgery Department, Aristide Le Dantec Hospital, Dakar, Senegal

\section{Corresponding Author:}

Ndong A

General Surgery Department, Aristide Le

Dantec Hospital, Dakar, Senegal

\section{Clinical photography in surgery: Knowledge, attitudes and practices in Dakar}

\author{
Ndong A, Diallo AC, Faye M, Ndiaye M, Diouf A, Faye PM, Niasse A, \\ Thiam JA, Sarr ISS, Seye Y, Gueye ML, Thiam O, Seck M, Touré AO, \\ Cissé $M$, Ka $O$ and Dieng $M$
}

DOI: https://doi.org/10.33545/surgery.2019.v3.i4d.244

\section{Abstract}

Background: Photography is very useful in medical practice, especially in surgery. Therefore, there are a growing number of legal issues related to the use of personal data. Our aim is to assess knowledge, attitudes and practices about the use of photography in surgery in Dakar.

Methods: This is a descriptive cross-sectional study involving surgeons and surgical trainees using photography in their practice in Dakar. An auto administered questionnaire was sent. The studied parameters were: the type of image and the mode of storage, the frequency of use, the advantages and disadvantages according to the user, the attitudes towards the informed consent, the respect for anonymity. Results: According to the type of pictures taken: $94.4 \%$ used it for clinical lesions; $90.3 \%$ for imaging images, $84.7 \%$ for per operative view. The type of device was a smartphone in $94.4 \%$, a tablet in $4.2 \%$ and a digital camera in $1.4 \%$. These images were stored on a smartphone in $77.8 \%$, a personal computer in $76.4 \%$ and online in $19.4 \%$. The benefits were noted in the follow-up of the patient $(76.4 \%)$, in the communication between physicians $(98.6 \%)$ and for a didactic purpose $(79.2 \%)$. The main disadvantage was the alteration of the contact with the patient (9.2\%). 30.6\% say that it is not mandatory to have the patient's informed consent. $75 \%$ of those surveyed said they had faced at least once, a patient's refusal when they took pictures.

Conclusion: Medical photography is really interesting in daily medical practice, especially in surgery. These results suggest misconceptions about ethical principles (informed consent, anonymity of patient and hospital). Since personal data is sensitive, medical photography must be used with caution.

Keywords: Photography, ethics, surgery, consent, anonymity, Senegal

\section{Introduction}

Photography is very useful in medical practice, especially in surgery. Communication is important in the success of any surgical team. With easy access to smartphones and other photographic devices, surgeons are increasingly using photography to communicate between them ${ }^{[1]}$. The interest of photography in surgery is based on the follow up of a disease, the response to treatment, the evaluation of medical, surgical and esthetic treatments, teaching of trainees and publication of scientific articles ${ }^{[2]}$. There are a growing number of legal issues related to the use of personal data. However, the nature of use, storage and information, informed consent practices for medical photography among surgeons has not been studied in our country.

Our aim is to assess knowledge, attitudes and practices about the use of photography among surgeon in Dakar

\section{Materials and Methods}

This is a descriptive cross-sectional study conducted between February 1 and March 31, 2018. It included surgeons and surgical trainees using photography in their practice in Dakar's hospitals. An auto administered questionnaire was sent.

The studied parameters were: The type of image and the mode of storage, the frequency of use, the advantages and disadvantages according to the user, the attitudes towards the informed consent, the respect for anonymity. 


\section{Results}

Out of 100 people contacted, 72 answered the questionnaire (12.5\% of surgeons and $87.5 \%$ surgical trainees). The mean age was $30.7 \pm 4.2$. The sex ratio $\mathrm{M} / \mathrm{F}$ was 5 (60 men and 12 women). The surgical specialties of persons surveyed are shown in Figure 1.

According to the type of pictures taken: $94.4 \%$ used it for clinical lesions; $90.3 \%$ for imaging images, $84.7 \%$ for per operative view. The majority of respondents (86.1\%) used photography more than once a week. The type of device was a smartphone in $94.4 \%$, a tablet in $4.2 \%$ and a digital camera in $1.4 \%$. These images were stored on a smartphone in $77.8 \%$, a personal computer in $76.4 \%$ and online in $19.4 \%$.

The type of images taken was essentially clinical lesions (94.4\%). The types of images are shown in Figure 2. The patient record was computerized only in $8.3 \%$. The benefits were noted in the follow-up of the patient $(76.4 \%)$, in the communication between doctors $(98,6 \%)$ and for a didactic purpose $(79.2 \%)$. The main disadvantage was the alteration of the contact with the patient $(9.2 \%) .30 .6 \%$ say that it is not mandatory to have the patient's informed consent and $61.1 \%$ say they do not make sure they have this consent before the image is taken. The anonymity of the patient was respected in $94.4 \%$, and that of the hospital in $41.7 \% .75 \%$ of those surveyed said they had faced at least once, a patient's refusal when they took pictures. The majority of respondents $(94.4 \%)$ said that they had never received training in taking pictures of a patient.

\section{Discussion}

Photography has a multiple interest in medical practice. The growth of its use is linked to the development of new technologies. In our study, practitioners used photography for recording clinical or intraoperative lesions or imaging exams. This allowed a better management by improving communication between doctors and patient follow-up. Images are an integral part of the patients' file. This is especially true in a surgical environment. According to Bhattacharya, they must be available for the follow-up of patients after surgery ${ }^{[3]}$. It can be used to illustrate the results of clinical examination, imaging or per operative exploration. It has an important role in postoperative follow-up with a prominent place in plastic surgery ${ }^{[4]}$. Photography also has an interest in traumatology, possibly to obtain expert medical opinion on fractures or dislocations ${ }^{[5]}$. This can be very useful in our context where there is a deficit of specialists.

Photography also has an academic interest. Indeed, during teaching for medical student and surgical trainees, it is necessary to use images with didactic purpose ${ }^{[3]}$.

All persons surveyed affirm to carry out themselves the photographs. This is explained in part by the easy access of smartphones ${ }^{[1]}$. This is the case in our study where they are used in the majority of cases $(94.4 \%)$.

The advantage of smartphones lies in the fact that they can send pictures quickly and cheaply. This could possibly be used to get the advice of older colleagues or other specialists. In an emergency setting, this would allow images to be transferred with significant time savings ${ }^{[1]}$.

In developed countries, there are clinical photographers hired by hospitals for imaging. This saves time for the doctor and improves the quality of the images ${ }^{[6]}$. They are trained to comply with the requirements of ethics and the protection of personal data, which ensures that images are stored and transferred appropriately ${ }^{[1]}$. However, whatever the use that is made of these images, there is always an ethical part to consider.
Photography often illustrates the privacy of patients. Images of the patient taken for medical purposes are an integral part of the patient's file. When used only for treatment and follow-up purposes, they do not strictly require the patient's consent as this is implicit in the patient's act of presenting for treatment. These images do not differ in any way from the medical written record, the imaging and biology reports ${ }^{[7]}$.

However, it is still important to explain the need for these recordings. To avoid misunderstandings in the relationship between the doctor and the patient, obtaining the informed consent of the patient should always be required, as well as the anonymity of the patient ${ }^{[8]}$.

Senegalese law as in many countries, is clear on the protection of personal data ${ }^{[9]}$. When the use of images is made outside the direct care, in the absence of informed consent or in case of violation of confidentiality, legal pursuits are possible.

In practice in our hospitals, medical photography is not standardized. For a better protection of the personal data, there should be available consent forms to be filled before each image taking. In each hospital, practical recommendations should be put in place for doctors in agreement with the national ethics committee. This would ensure greater attention to respect for confidentiality and ethics.

In our study showed an important lack in the training (majority of respondents $(94.4 \%)$ had never been trained about medical photography). Particular emphasis should be placed on the training about medical photography and the ethical issues they may create.

Moreover, the patients' file is less frequently computerized in our context $(8.3 \%$ in our study). The storage of images in smartphones or personal computers thus increases the risk of non-respect of confidentiality ${ }^{[10]}$. Even when removed from the camera, images are still traceable. This can pose a real privacy problem ${ }^{[1]}$.

Clinical photography has a key place in daily medical practice, especially in surgery. These results suggest misconceptions about ethical principles (informed consent, anonymity of patient and hospital). Since personal data is sensitive, photography must be used with caution. In our context, it would be important to carry out further studies to make practical guidelines for medical photography.

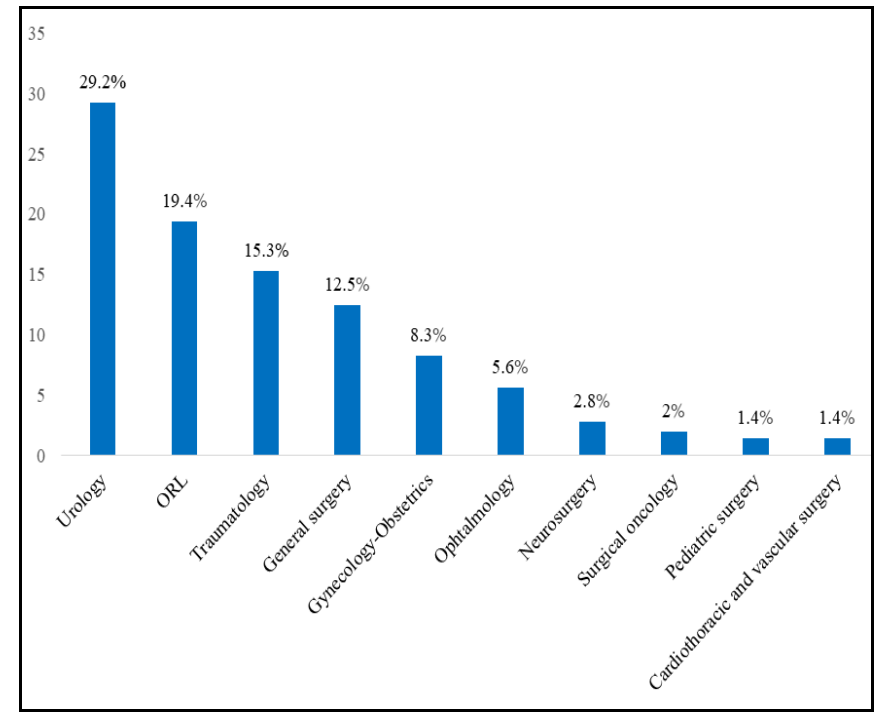

Fig 1: Distribution of surgical specialties of persons surveyed 


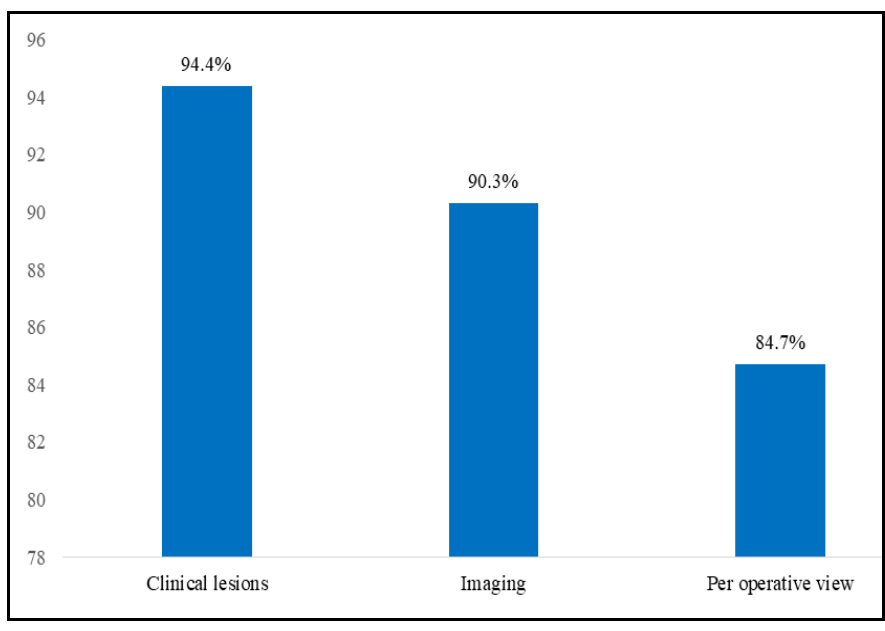

Fig 2: Distribution of types of images taken

\section{Declarations}

\section{Acknowledgments}

None

\section{Financial support and sponsorship}

None

\section{Conflicts of Interest}

"All authors declared that there are no conflicts of interest."

\section{References}

1. Dala-Ali BM, Lloyd MA, Al-Abed Y. The uses of the iPhone for surgeons. Surg J R Coll Surg Edinb Irel. 2011; 9:44-8.

2. Rimoin L, Haberle S, DeLong Aspey L et al. Informed Consent, Use, and Storage of Digital Photography Among Mohs Surgeons in the United States. Dermatol Surg. 2016; 42:305-9.

3. Bhattacharya S. Clinical photography and our responsibilities. Indian J Plast Surg Off Publ Assoc Plast Surg India. 2014; 47:277-80.

4. Aveta A, Filoni A, Persichetti P. Digital Photography in Plastic Surgery: The Importance of Standardization in the Era of Medicolegal Issues. Plast Reconstr Surg. 2012; 130:490.

5. Chandhanayingyong C, Tangtrakulwanich B, Kiriratnikom T. Teleconsultation for emergency orthopaedic patients using the multimedia messaging service via mobile phones. J Telemed Telecare. 2007; 13:193-6.

6. Burns K, Belton S. Clinicians and their cameras: policy, ethics and practice in an Australian tertiary hospital. Aust Health Rev 2013; 37:437-41.

7. Cull PG, Gilson CC. Confidentiality of illustrative clinical records-a code of practice, guidance notes and recommendations. J Audiov Media Med. 1986; 9:124-130.

8. Burns K, Belton S. Click first, care second photography. Med J. 2012; 197:265.

9. Loi $n^{\circ} 2009-17$ portant Code d'Ethique pour la Recherche en Santé, Sénégal. Available from: http://www.jo.gouv.sn/spip.php?article7557/.

10. Van der Rijt R, Hoffman S. Ethical considerations of clinical photography in an area of emerging technology and smartphones. J Med Ethics. 2014; 40:211-2. 